\title{
Analysis of visually guided eye movements in subjects after whiplash injury
}

\author{
Francesco Dispenza ${ }^{\mathrm{a}, *}$, Rosalia Gargano ${ }^{\mathrm{b}}$, Navneet Mathur ${ }^{\mathrm{c}}$, \\ Carmelo Saraniti ${ }^{\mathrm{b}}$, Salvatore Gallina ${ }^{\mathrm{b}}$ \\ ${ }^{a}$ Dipartimento Discipline Chirurgiche e Oncologiche - U.O. Otorinolaringoiatria, Università degli Studi di Palermo, Italy \\ ${ }^{\mathrm{b}}$ Dipartimento Neuroscienze Cliniche - U.O. Otorinolaringoiatria, Università degli Studi di Palermo, Italy \\ ${ }^{\mathrm{c}}$ RNT Medical College, Udaipur, India
}

Received 14 March 2010; accepted 25 August 2010

Available online 23 October 2010

\begin{abstract}
Objective: The aims of present research were to analyze the visually guided eye movements of subjects suffering from the consequences of whiplash injury and the possibility to differentiate patients from feigning subject. We analyzed the role of video-nystagmography for clinical and forensic aspects.

Methods: It was a prospective case-control study. Detailed history was taken and patients were thoroughly investigated. Smooth pursuit and saccadic eye movements were assessed in 33 patients affected by imbalance following a whiplash injury. A control group of 20 subjects was also evaluated. All tests were executed in neutral neck position and after left and right trunk rotation.

Results: The $t$-test, applied to all parameters showed that difference of the parameter between the groups was not statistically significant. Conclusion: The visually guided eye movement evaluation does not seem to offer a clinically relevant method to differentiate patients suffering from the effects of whiplash injury from normal subjects.
\end{abstract}

(C) 2010 Elsevier Ireland Ltd. All rights reserved.

Keywords: Whiplash; Trauma; Vertigo; Saccadic; Optokinetic; Smooth-pursuit

\section{Introduction}

The evaluation of the vestibular system disease is always a challenge for the clinician. Symptoms of imbalance or true vertigo, complained by patients, may be present in numerous diseases and can be due to lesion at different levels in vestibular system. The quantification of vestibular damage is also difficult in case forensic tests are done. For these reasons it is mandatory to employ instrumental tests to verify without bias the symptoms reported after an injury and to detect patients who are feigning [1].

The equilibrium is the result of a perfect integration of input from the ocular, proprioceptive and vestibular systems.

\footnotetext{
* Corresponding author at: Via Oreto 339, 90124 Palermo, Italy. Mobile: +39 3334565471 .

E-mail address: francesco.dispenza@gmail.com (F. Dispenza).
}

The whiplash injury is a traumatic lesion due to rapid flexion-extension movement of the cervical column. Such trauma to the neck causes an alteration of signals reaching from the cervical proprioceptive system to the central vestibular system and thus affects equilibrium. Balance problems are reported by 5-50\% of patients of whiplash injury $[1,2]$. The whiplash injury is generally due to car collision and is the first cause of insurance claims. About $15-20 \%$ of cases develop the so-called late whiplash syndrome with persistent complaints including headache, vertigo, instability, nausea and tinnitus [2].

The cervical trauma may increase the discharge of muscles' proprioceptive receptors of the neck [3]. As described in literature the abnormal input coming from neck receptors interfere with normal activity of vestibular system and may result in alteration of vestibular-ocular reflexes $[4,5]$. 
A whiplash injury can induce an elongation of the cervical column that may reach $5 \mathrm{~cm}$ and, as consequence, a stretching of the medulla, brainstem and also cerebellum as reported in literature. Some clinicians noted also alteration of saccadic and smooth pursuit movements [6-9].

The neural pathways of both system saccadic and smooth pursuit extend from cerebral cortex to oculomotor nuclei trough the cerebellum. The alterations of ocular movements may represent a sensitive markers of central nervous system damage. For such reason the attentions of clinicians were focused on eye movements to find some justification of dizziness after a whiplash injury. Furthermore Hinoki et al. founded an increased activity of cervical proprioceptors and a concomitant dysfunction of central nervous system after a traumatic distortion of cervical tract [10].

Our work's aim was to evaluate the visually guided eye movements in patients of whiplash injury, by the analysis of the saccadic eye movements and smooth pursuit movements matching the data of whiplash patients with a control group, to make an attempt to clarify such argument.

\section{Materials and methods}

A case-control clinical evaluation was done on two groups in the year 2008. The first group included patients of whiplash injury that were referred to our department. The exclusion criteria for the first group were: history of vertigo before the whiplash injury, ear disease or hearing loss, and of central nervous system pathology. The control group consisted of normal subjects without vestibular symptoms or general disease, negative history for head and neck disease or trauma. The first group was subdivided in 3 subgroups, depending upon the interval of time between trauma and evaluation: Group A (1-2 months), Group B (2 to 6 months) and Group C (7-12 months). This further subdivision was done to find a relation between symptoms persistence and time of injury.

The evaluation included: complete head and neck examination, clinical vestibular tests, pure tone audiometry and video-oculography/video-nystagmography with infrared system. All the tests were performed in an isolated room with dim light. During the tests the patients were seated at $42 \mathrm{~cm}$ from the display. The smooth-pursuit movement was evaluated by following an oscillating illuminated target on a 29 -in. screen; the target velocity was regular $(18 \% \mathrm{~s})$ and the oscillating movements were from center to right, back to the center and then center to left. Each trial was of 20 cycles of $57 \mathrm{~s}$. The saccadic test was performed by asking the patient to watch the target on a horizontal plane; the frequency was $0.4 \mathrm{~Hz}$ and the amplitude was $\pm 20^{\circ}$. The tests were done in normal position (central) and repeated after left and right $30-^{\circ}$ trunk rotation with hand-fixed head by operator for at least $60 \mathrm{~s}$. The same operator performed all tests. The presence of spontaneous nystagmus in the various positions was recorded. The parameters analyzed in saccadic movement evaluation were: latency, velocity and accuracy. Our cutoff parameters to consider the results as pathological were: value more than $200 \mathrm{~ms}$ for latency, a score under $77 \%$ for accuracy and a highest velocity under $530 \%$ s. The smooth-pursuit movement analysis was evaluated measuring the gain (eye velocity/target velocity) and the parameter of normality was a value of $0.88 \pm 0.2$.

The values of the data evaluated were averaged to compare all the groups and subgroups. A parametric test ( $t$ test) was done to demonstrate any significant difference between analyzed parameters.

All patients and normal subjects enrolled in the study were informed and they signed the informed consent. Our Institutional Review Board approved the study.

\section{Results}

The first group included 37 patients, of which 23 were males. The mean age was 36.5 years (range 21-53 years). All patients had a history of whiplash injury (without loss of consciousness) of 12 months duration. All patients in the first group complained of persistent imbalance after the trauma. Four patients were excluded from the evaluation: 3 patients with post-traumatic benign paroxysmal positional vertigo (BPPV) and 1 patient with asymptomatic bilateral hearing loss in $4-8 \mathrm{kHz}$ (PTA $45 \mathrm{~dB}$ ). The audiological examination did not show any hearing loss in the remaining patients. The first group was subdivided 3 subgroups based on interval of trauma to evaluation as mentioned before. The group A comprised of 11 patients with mean age of 34.1 years. The group B included 11 patients with mean age of 37.6 years and the group $\mathrm{C}$ consisted of 11 patients with mean age of 37.6 years.

The control group had 23 asymptomatic subjects, of which 12 were male. The mean age of the control group was 30.4 years (range 19-49 years). All subject of the control group matched the inclusion/exclusion criteria. The audiological examination was normal in all cases but 3 ( 2 males and 1 female) were excluded from the study.

The results of the analysis are summarized in Tables 1 and 2, where the mean and the standard deviation of all parameters tested of both groups are reported. No statistically significant differences $(p>0.05)$ were noted between the groups and between positions of the head as respect to the trunk. No spontaneous nystagmus related to the neck rotation was recorded. The sex and the age were not related with results of the tests.

\section{Discussion}

The effects of trauma on cervical column were first described by Crowe in 1928 and by Gray and Abbott in 1953 $[11,12]$. Significant injuries can occur even at low speed collision but simulated accidents have shown that a 5-miles an hour rear-end car crash can result in a positive 
Table 1

Mean and standard deviation (SD) of parameters tested in neutral position.

\begin{tabular}{|c|c|c|c|c|}
\hline & Control Group & Group A & Group B & Group C \\
\hline Smooth-pursuit gain (SD) & $0.87( \pm 0.04)$ & $0.85( \pm 0.03)$ & $0.87( \pm 0.04)$ & $0.87( \pm 0.03)$ \\
\hline Saccadic velocity in degree/sec (SD) & $573.05( \pm 25.25)$ & $574( \pm 31.05)$ & $564.9( \pm 28.67)$ & $574.7( \pm 33.39)$ \\
\hline Saccadic latency in degree/sec (SD) & $161.63( \pm 15.67)$ & $154.6( \pm 10.36)$ & $155.2( \pm 14.25)$ & $156.1( \pm 11.68)$ \\
\hline Saccadic accuracy in \% (SD) & $0.84( \pm 0.05)$ & $0.81( \pm 0.06)$ & $0.84( \pm 0.07)$ & $0.82( \pm 0.06)$ \\
\hline
\end{tabular}

Table 2

Mean and standard deviation (SD) of parameters tested in neutral position and after rotation in the patients group.

\begin{tabular}{|c|c|c|c|}
\hline & Neutral position & $30^{\circ}$ left rotation & $30^{\circ}$ right rotation \\
\hline Smooth-pursuit average value of gain (SD) & $0.87( \pm 0.04)$ & $0.86( \pm 0.03)$ & $0.87( \pm 0.04)$ \\
\hline Saccadic average value of velocity in degree/sec (SD) & $571( \pm 34.1)$ & $572.05( \pm 24.35)$ & $565.9( \pm 27.47)$ \\
\hline Saccadic average value of latency in degree/sec (SD) & $155.3( \pm 13)$ & $161.73( \pm 13.07)$ & $155.4( \pm 14.35)$ \\
\hline Saccadic average value of accuracy in \% (SD) & $0.83( \pm 0.06)$ & $0.83( \pm 0.06)$ & $0.84( \pm 0.06)$ \\
\hline
\end{tabular}

acceleration of $8.2 \mathrm{G}$ of the head [13]. The increasing numbers of car collisions have resulted in an increased number of hospital admissions due to the whiplash injury. Consequently, the insurance claims and the need for forensic evaluation of the damages have increased which spurred us to conduct the present study.

The whiplash injury produces a distortion of the cervical column causing lesions of several cervical sites: muscles, ligaments, vertebral joints, vessels and nerves. The more serious injury could be the stretching of the cervical spine during the flexion-extension of the head. Such sudden and violent movement may result in an elongation of the medulla oblongata or a distention of the cerebellum. Pathophisiologically it is possible to note a central nervous system weakness following a whiplash injury. With respect to inner ear, the exact nature of the lesion is not known but some possible explanation may be: transient ischemia by vertebral artery compression, hemorrhage into labyrinth, direct labyrinthine concussion and noise of the collision.

The typical acute symptoms after whiplash includes: neck pain, headache, paraesthesia of upper cervical dermatomes, dizziness or imbalance and tinnitus. The majority of patients show spontaneous recovery after few months of symptomatic treatment. In some patients the symptoms may persist.

The imbalance is the most incapacitating symptom after whiplash injury $[14,15]$. The cervicogenic dizziness may occur after trauma of the cervical column however cervical vertigo remains a highly controversial entity $[7,15,16]$.

A neurotological evaluation should be performed in an attempt to find a possible cause and to find out if treatment is possible. The examination includes the assessment of peripheral labyrinth and vestibulo-ocular reflex system by clinical vestibular tests and caloric test. The tests include the evaluation of visually guided eye movements by videooculography/video-nystagmography.
Previous studies have scarcely demonstrated any relationship between peripheral dysfunction and trauma. Some studies present in literature have shown positional nystagmus and unilateral hyporeflexia in patients of whiplash injury [9,17-22]. Ettlin et al. reported peripheral vestibular deficits in only two cases among 18 after whiplash injury [23]. However all these reports have not used a standard value as benchmark or any proper control group.

The most common type of true vertigo following whiplash injury is BPPV [24]. Following the trauma the otoliths are detached from utricle and displaced within the labyrinth. The diagnosis is confirmed by positional tests. Such patients that present with a true inner ear disease should be separated from those subjects with imbalance due to neck trauma, as we have done in our series to find a true cervical nystagmus, in other words the true presence of nystagmus or eye movement disturbance related to the neck proprioception abnormality (cervical nystagmus).

It is widely considered that a whiplash injury may induce a disorder of neck proprioception caused by forces applied to the neck in the course of the read-end accident. A clinical sign of such disturbance is the so-called "cervical nystagmus", a nystagmus arising from neck rotation with no labyrinthine stimulation. We agree with Fischer et al. in distinguishing either spontaneous or positional nystagmus arising in certain static head positions from the previously reported "cervical nystagmus", because static labyrinthine stimulation may exist [25]. Several Authors failed to demonstrate a relationship between nystagmus and neck proprioceptors' stimulation [18,19,26]. Also in our series any spontaneous and/or "cervical nystagmus" was noted neither in neutral position nor after $30^{\circ}$ left/right rotation. We preferred a $30^{\circ}$ rotation to avoid any restriction of the rotation due to the trauma because of testing the patients.

The infrared video-oculography/video-nystagmography allowed us to detect even slight alterations of saccadic and smooth-pursuit movements. This would have been to our 
advantage in revealing a feigning subjects if the damage of neck proprioceptors had produced a recognizable nystagmus or some abnormality of cervico-ocular reflex.

As mentioned before, the neural pathways of ocular movement systems extend from cerebral cortex to oculomotor nuclei trough the cerebellum and the interruption of such ways induces an alteration of ocular movements. Excluding those patients with a known lesion of central nervous system (i.e.: spine, brainstem) after the trauma of the head and focusing the attention only to subjects that had a cervical column disturbance, the prevalence of ocular movements alteration may be very low or totally absent as our series showed, probably because an interruption of the central ways is improbably for a common whiplash trauma.

The functional performance of voluntary oculomotor systems depends upon attentional processing and in patients that had a whiplash injury was demonstrated a reduction of the attention and of information processing velocity [27]. We believe that most of the alterations (increased latency or decreased gain) of saccadic and smooth-pursuit movements, reported elsewhere in whiplash patients, may be due only to a diminishing of attention processing. As Mosimann et al. demonstrated, only intentional saccades are impaired in whiplash patients, while reflexive eye movements are normal [28]. In fact also the searching of nystagmus after cervical torsion in both sides was not significant. Our results showed a normality of all parameters tested in patients of whiplash injury; consequently we can exclude in whiplash patients a correlation between cervical column distortion and alteration of systems that control the saccadic and smooth-pursuit movements. The data recorded in this study is not in accordance with those reported by some authors that noted alterations of optokinetic reflexes and saccadic in theirs cases [7,10,29-31]. Our findings agree with those reported by Fischer et al. $[18,19]$ and Kongsted et al. $[32,33]$.

The absence of differences between normal subjects and patients of whiplash injury underscores the futility of the ocular movements analysis in patients complaining cervical column trauma without central nervous system damages in case of litigation following car collision.

\section{Conclusions}

Caution is required in interpreting the abnormalities of eye movements in cases of whiplash injury as robust data is not available to support the presence of abnormalities in eye movements. Attention to methods of evaluation should be kept in mind to avoid mixing up a nystagmus arising from labyrinth stimulation with "cervical nystagmus". Furthermore, the reproducibility of the alteration found should be verified to exclude any deliberate alteration by feigning subjects or by decreasing of concentration. The study of ocular movements does not offer a valid tool to differentiate a true patient from a feigning subject after whiplash injury.

\section{References}

[1] Mallinson AI, Longridge NS. Dizziness from whiplash and head injury: differences between whiplash and head injury. Am J Otol 1998;19:814-8.

[2] Claussen CF, Claussen E. Neurootological contributions to the diagnostic follow-up after whiplash injuries. Acta Otolaryngol Suppl 1995;520:53-6.

[3] Nederhand MJ, Hermens HJ, Jzerman MJ, Turk DC, Zilvold G. Cervical muscle dysfunction in the chronic whiplash associated disorder grade II (WAD-II). Spine 2000;15:1938-43.

[4] Brandt T, Bronstein AM. Cervical vertigo. J Neurol Neurosurg Psychiatry 2001;71:8-12.

[5] Treleaven J, Jull G, Sterling M. Dizziness and unsteadiness following whiplash injury: characteristic features and relationship with cervical joint position error. J Rehabil Med 2003;35:36-43.

[6] Sances A, Weber RC, Larson SJ, Cusick JS, Myklebust JB, Walsh PR. Bioengineering analysis of head and spine injuries. Crit Rev Bioengng 1981;6:79-122.

[7] Hildingsson C, Wenngren BI, Bring G, Toolanen G. Oculomotor problems after cervical spine injury. Acta Orthop Scand 1989;60:513-6.

[8] Hildingsson C, Wenngren BI, Toolanen G. Eye motility dysfunction after soft-tissue injury of the cervical spine. Acta Orthop Scand 1993;60:513-6.

[9] Oosterveld WJ, Kortschot HW, Kingma GG, de Jong HA, Saatci MR. Electronystagmographic findings following cervical whiplash injuries. Acta Otolaryngol 1991;111:201-5.

[10] Hinoki M. Vertigo due to whiplash injury: a neurotological approach. Acta Otolaryngol Suppl 1985;419:9-29.

[11] Gray JR, Abbott KH. Common whipplash injuries to the neck. JAMA 1953;152:1698-704.

[12] Crowe HE. Injuries to the cervical spine. In: Paper presented at the meeting of the western orthopaedic association; 1928.

[13] Henderson B. Putting the $5 \mathrm{mph}$ injury threshold to the test. Pers Injury Law J 2006;12-4.

[14] Evans RW. Some observations in whiplash injuries. Neurol Clin 1992;10:975-97.

[15] Compere WE. Electronystagmographic findings in patients with whiplash injuries. Laryngoscope 1968;78:1226-33.

[16] Bogduck N. The anatomy and pathophysiology of whiplash. Clin Biomech 1986;1:92-101.

[17] Chester Jr JB. Whiplash, postural control, and the inner ear. Spine 1991;16:716-20. Phila Pa 1976.

[18] Fischer AJ, Huygen PL, Folgering HT, Verhagen WI, Theunissen EJ. Hyperactive VOR and hyperventilation after whiplash injury. Acta Otolaryngol Suppl 1995;520(Pt 1):49-52.

[19] Fischer AJ, Huygen PL, Folgering HT, Verhagen WI, Theunissen EJ. Vestibular hyperreactivity and hyperventilation after whiplash injury. $\mathrm{J}$ Neurol Sci 1995;132:35-43.

[20] Pang LQ. The otological aspects of whiplash injuries. Laryngoscope 1971;81:1381-7.

[21] Rubin W. Whiplash with vestibular involvement. Arch Otolaryngol 1973;97:85-7.

[22] Toglia JU, Rosenberg PE, Ronis ML. Posttraumatic dizziness, vestibular, audiologic, and medicolegal aspects. Arch Otolaryngol 1970;92:485-92.

[23] Ettlin TM, Kischka U, Reichmann S, Radii EW, Heim S, Wengen D, Benson DF. Cerebral symptoms after whiplash injury of the neck: a prospective clinical and neuropsychological study of whiplash injury. $\mathbf{J}$ Neurol Neurosurg Psychiatry 1992;55:943-8.

[24] Fitzgerald DC. Head trauma: hearing loss and dizziness. J Trauma 1996;40:488-96.

[25] Fischer AJ, Verhagen WI, Huygen PL. Whiplash injury. A clinical review with emphasis on neuro-otological aspects. Clin Otolaryngol Allied Sci 1997;22:192-201.

[26] Holtmann S, Reiman V, Schops P. Zur klinischen Bedeutung zervikookularer Reaktionen. Laryngol Rhinol Otol 1993;72:306-10. 
[27] Radanov B, Dvorak J, Valach L. Cognitive deficits in patients after soft tissue injury of cervical spine. Spine 1992;17:127-31.

[28] Mosimann UP, Müri RM, Felblinger J, Radanov BP. Saccadic eye movement disturbances in whiplash patients with persistent complaints. Brain 2000;123:828-35.

[29] Armato E, Ferri E, Garcia Purrinos F. Resultados del analisis videonistagmografico en la patologia vestibular post-traumatica. Acta Otorrinolaringol Esp 2001;52:567-74.

[30] Meran A, Rohner Y, Pfaltz CR. Zur Symptomatologie und Diagnostik der vestibularen Funktionsstorungen nach Schadel-Hirntrauma. HNO 1978;26:41-8.
[31] Davies RA, Luxon LM. Dizziness following head injury: a neurootological study. J Neurol 1995;242:222-30.

[32] Kongsted A, Jorgensen LV, Leboeuf-Yde C, Qerama E, Korsholm L, Bendix T. Are altered smooth pursuit eye movements related to chronic pain and disability following whiplash injuries? A prospective trial with one-year follow-up. Clin Rehabil 2008;22:469-79.

[33] Kongsted A, Jorgensen LV, Bendix T, Korsholm L, Leboeuf-Yde C. Are smooth pursuit eye movements altered in chronic whiplash-associated disorders? A cross-sectional study. Clin Rehabil 2007;21: 1038-49. 